\title{
Improving contemporary approaches to the master planning process
}

Husam Al Waer

School of the Environment, Architecture and Planning, University of

Dundee, Dundee, Scotland

Master planning has undergone a revival in recent years. However, significant demographic and social changes are also occuring amid constraints resulting from the current economic stagnation, reduced public spending and the drive to respond to environmental imperatives. These conditions challenge the feasibility of applying master planning practices as they were conceived of in the past. The traditional view was that master planning was a design-led activity concerned with the architectural form of buildings, spaces and infrastructures. This is outdated and inadequate for coordinating the plural processes of developing sustainable places that satisfy social, functional, economic and environmental requirements as well as realising visually pleasing townscapes. Master planning requires both a business planning component, without which there is no delivery, and a governance component, without which the physical strategy has no legitimacy. A more adaptive master planning approach is required. The paper proposes how a flexible master planning process can provide a basis of a suitable approach for the development of sustainable settlements.

\section{Introduction}

The paper discusses whether the master planning approach remains a relevant planning and development tool in the prevailing and foreseeable conditions of urban development in the UK, and assesses the form of master planning that may be most relevant for planning and developing sustainable settlements. The paper is organised in two sections. The first section reviews the nature of contemporary development and establishes the factors that a master planning system has to accommodate in order to be effective. The second section identifies the elements of the new master planning approach that is required for the better management of master planning. The paper concludes with a discussion of how this master planning process can become the basis of future development practice.

\section{The nature of contemporary development}

The goals of providing better living conditions and reviving the economy underpinned the use of master plans in the post-war reconstruction of cities and the creation of new towns in the UK. The traditional view of master planning prescribed making a blueprint of the content and appearance of a site or place when it had been developed. Master planning was a management practice for managing the physical processes necessary for realising the development of urban places. The master plan design was concerned with relating physical parts to a larger whole, thus prescribing the final form of the built environment to be achieved on a site through the development process. On occasion master planning was conceived at the city level to provide a strategic infrastructural framework to guide the growth of the city but more often it was applied as a management practice at the level of the local areas and site. Peripheral housing estates, new towns and inner-city redevelopment were the products of the application of the master planning approach. The focus of this paper is on the development of residential settlements.

Place development in the post-war years has not always brought about lasting benefits. The master planning process has been criticised for focusing on the end state and as using a command approach. Ironically, the subsequent implementation of the plan has often been disjointed and incomplete as implementation was tackled as a sequential and fragmented process. The type of built environment often resulting from this practice of master planning has contributed to the emergence of the key social issues evident around the country in contemporary times. These issues include the fragmentation of communities and loss of civic cohesion; unmet social needs and overstretched public services; the emergence of dysfunctional neighbourhoods; and the creation of built environments of low social, environmental and market value (Adams and Davies, 2012; Adams et al., 2010; Carmona et al. 2010; Ellin, 
Urban Design and Planning

Volume 167 Issue DP1
Improving contemporary

approaches to the master

planning process

Al Waer
2012; Lawlor, 2011; Tiesdell and Adams, 2011; Trained, 2011). We will return to these issues later in this paper.

The failure of mass-build architectural solutions to fulfil the demand for housing environments satisfying popular expectations, alongside the resurgence of market-led development and the improved scientific understanding of the impacts of economic growth on the natural environment, have been significant factors in the general recognition that the planning of the urban environment cannot be limited to the use of a physical planning and design-based approach.

Master planning has become a less architectural process. 'The long argued distinctions between activity and movement, between land use and transport, between production and consumption have begun to dissolve' (Solesbury, 1998 in Cooper et al., 2009: p. 190). It is accordingly necessary to revisit the conceptualisation and methodology of master planning. The understanding that 'Master-plans are, in essence, site- and form-based development control mechanisms' has been expanded in multiple ways such that 'the term is frequently used to encompass a broad range of concepts' (Bell, 2005: p. 84). Master planning today is what takes place when an area is substantially redeveloped through co-related development projects. Reconceived, master planning combines collaborative framing of a realistic vision of the planned development of a community; the provision of an enabling infrastructure and the setting out and delivery of the built form. Master planning is thus proactive. It is undertaken as a means to achieve public and private outcomes that market activity focused on individual property developments would not achieve so fully, if at all.

There has been an 'upsurge in master-planning' (Sparks, 2000: p. 13) in the UK since the late 1990s. This momentum has been stimulated by policy interest and a number of important publications and policies advocating the use of master plans, most notably the Urban Task Force report (1999); the Planning Policy Statement 3: Housing (DCLG, 2006); the Localism Act (DCLG, 2011) and recently guidance published by the Commission for Architecture and the Built Environment (CABE, 2011). Bell (2005: p. 82) suggests that master planning has become more commonly used because of the increased interest by professionals and policymakers in the value of better urban design in urban regeneration and also the greater reliance on public-private partnership arrangements in cities using master plans to help coordinate decisions, resources and action. The master planning process is used to coordinate the provision of roads, drainage, other utilities, social housing and market-provided housing, educational facilities, other public services provision and public amenities including open spaces. In short, master planning has been seen as a process for generating better outcomes when the management of the process effectively coordinates the inputs of a complexity of interests. What a more effective master planning process requires are people who know how to collaborate to manage change and to deliver a strategic vision. Such a place production process aims to foster a sustainable community. It requires an inclusive and integrated approach to development (Adams and Tiesdell, 2012).

The factors that influence the uses and time-scale of the development of a local place are of primary importance for determining the manner of the collaborative place production process. Urban development in the first decade of the twentyfirst century has gone through a dramatic cycle of boom and bust and the financial and economic forces that have brought about the collapse of investment in development across the UK run alongside macro-trends of environmental, demographic, social, political and technological change, all of which impact on urban places and communities.

While this is not an exhaustive list, three main themes emerge as significant influences in the contemporary development of local communities. These are climate change, economic austerity and social change. The trends of change compound and interact with complex effects of the environment, investment and social wellbeing. We must explore these themes and understand their implications (Rogers et al., 2012). The features of these themes are summarised in the following paragraphs (see Figure 1).

\subsection{Climate change}

Climate change accelerated to the top of the political agenda fuelled by a consensus across scientific institutions that action needs to be taken to mitigate its negative impact. Concern about the environmental costs of contemporary urban lifestyles, in particular the global impacts of increased emissions of greenhouse gases (GHGs), prompted the call for developing urban places consistent with the principles of environmental sustainability. The UK government set a target for reducing GHG emissions by $80 \%$ by 2050 based on 1990 levels. Achieving this target is challenging, owing to the wide range of ages and conditions of the UK housing stock. These concerns require planners to rethink the built form of places to promote their resilience to flooding and walkability for residents to mitigate the effects of climate change (McInroy and Longlands, 2010: p. 8).

\subsection{Economic austerity}

Since the 1980s in the UK development has been increasingly market led. However, there has been insufficient development of residential housing to prevent a substantial increase in house prices. Households on moderate incomes are no longer able to afford to buy a new dwelling. Consequently, it is no longer commercially viable for developers to build low-cost housing for sale. Development markets have returned to the cycle of 


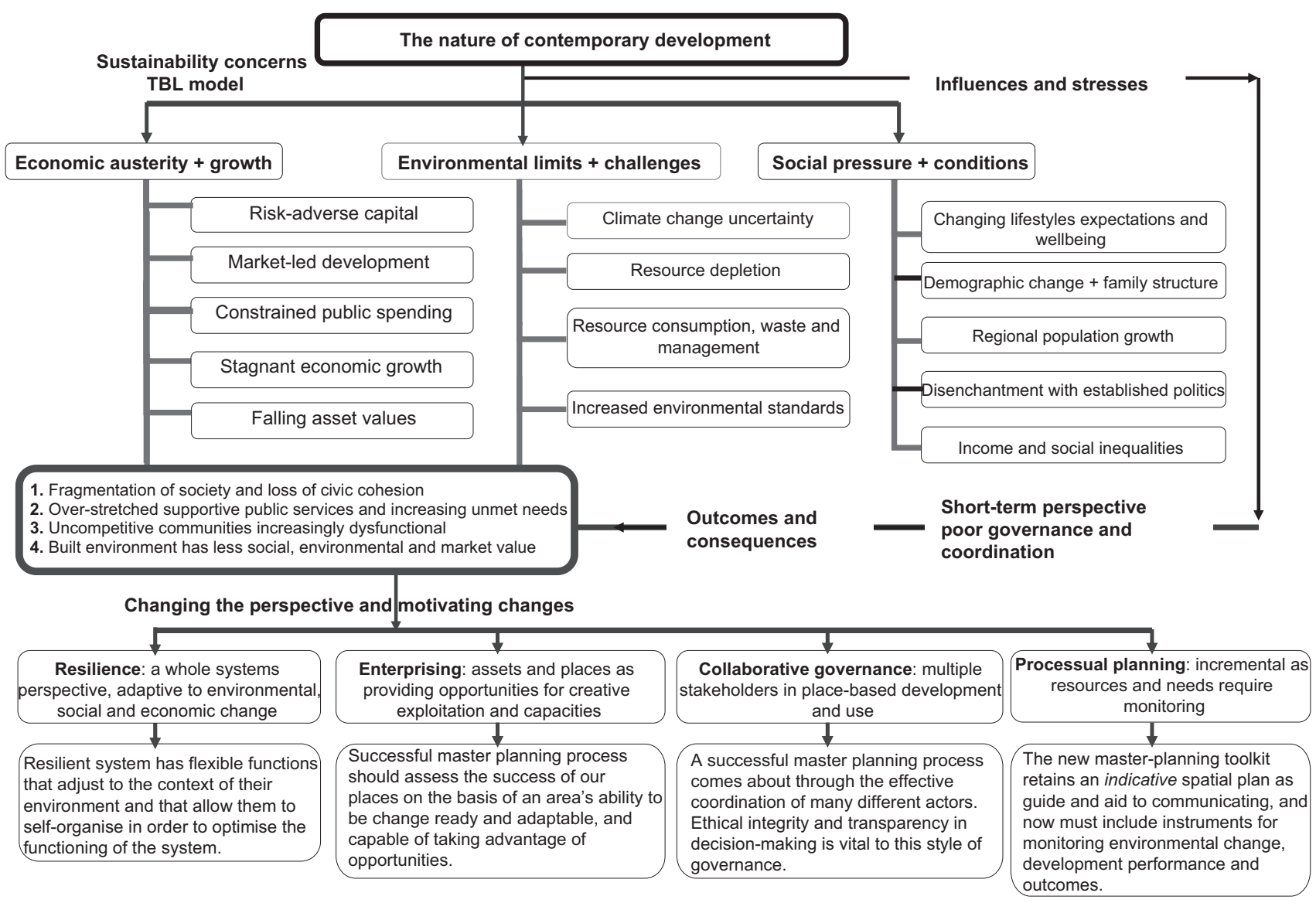

Figure 1. The nature of contemporary development in the UK. (Adams and Davies, 2012; Adams and Tiesdell, 2012; Adams et al., 2010; AlWaer et al., 2013; Bell, 2005; Boyko et al., 2005; CABE, 2011; Carmona et al., 2010; Cooper and Symes, 2009; Ellin, 2012;
Lawlor, 2011; Lombardi et al., 2012; McInroy and Longlands, 2010; Roberts, 2009; Rogers et al., 2012; Trained, 2011; Urban Design Protocol, 2011; Madanipour, 2006; Tiesdell and Adams, 2011) boom and bust. There is pessimism in the UK that there will be real growth in household incomes in the foreseeable future. One conclusion to be drawn is that new policies and financing solutions are needed for affordable new housing.

\subsection{Social change}

Changes in the structure of the population and the locations where people choose to live are of concern to developers as well as to public and private agencies that aim to deliver services to local communities. Demographic trends in the UK indicate that there is a growth in the numbers of elderly households and of children. People continue to relocate between regions to secure employment and the population of south-east England continues to rise. It is the need to house the rising population in south-east England that will be a main driver of town extensions and new settlements into the foreseeable future.
Whereas technological advances have profoundly affected lifestyles, perhaps a greater influence in future years will be the recent huge expansion in the accessibility of knowledge and information to most groups. The influence of a better educated community accessing ideas and know-how and making new individual and collective decisions about their lifestyle choices accordingly may be increasingly significant. Novel and creative behaviour can be expected and as communities we may have the capacity for greater innovation in shaping our places. There are indications that the practice of master planning has already appreciated this potential. The increasing use of the design charrette as a method of conducting community workshops is a manifestation of the recognition that the public can contribute to envisioning the future characteristics of changing communities.

The complexity of urban systems, the rapidity of climate, technological, economic, market and social change, and a 
Urban Design and Planning

Volume 167 Issue DP1
Improving contemporary

approaches to the master

planning process

Al Waer greater recognition of plural interests necessitating participatory engagement now challenge the process of master planning.

Traditionally, a master plan was described as a physical design strategy. However, it is now envisaged that the master planning process encompasses more than the configuration of urban design. The process requires both a business planning component without which there can be no delivery; and a civic governance process without which the physical strategy has no legitimacy. In the next section the emerging paradigms that will contribute to a better master planning approach in the twenty-first century are identified.

\section{A better master planning process}

Master planning cannot fix everything, but the master planning process envisaged for the twenty-first century needs to be seen as a 'framework for managing change over a wider area (and over a lengthy time period) rather than just the spatial rendering of a property development on a site' (Bell, 2005: p. 8). Master planning involves a continuous process of decision-making. As stated above, to develop a sustainable community requires not only making decisions about the spatial form of a place but it also requires awareness of a range of decisions made in a complex of related fields. The most significant of these fields are the life chances and lifestyle choices of the user community; the regulatory requirements; the provision of public services; and the investment and asset maintenance decisions on the infrastructure and housing. The choices made in these fields have significant implications for the deliverability of the built environment and positive experience of users. Accordingly, the master planning process is not a simple matter of urban design. It has to be moved forward in a complex and evolving environment of decisionmaking, which in turn is influenced by dynamic macroenvironmental factors. Moreover, in the economic conditions prevailing in the UK settlements are not constructed overnight. Development is incremental. It occurs over time and is delivered by differing agencies both public and private. Therefore, four features lying at the heart of improving the master planning process have to be recognised: creating resilient places; places for enterprising communities; creating places for collaborative governance and processual planning (planning as a process).

\subsection{Creating resilient places}

Creating resilient places requires a whole-systems perspective that is adaptive to environmental, social and economic change, that is, scenario-based planning. To focus on the long-term outcomes, resilience is a key concept for future master planning. 'Successful places are resilient and robust: they adapt well to change and sustain themselves in various guises over generations' (Adams and Davies, 2012: p. 4). The resilience of sustainable places lies in their capacity to respond to forces of change in such a manner that the place is viewed positively in the eyes of the community who live in and use it. For a place to be resilient it must be viewed as the nexus of interconnected managed systems, social, economic and environmental, which function in a synergistic fashion. The systems have to be aligned to each other so as to support the ability of the place to be gradually adapted to accommodate the pressures and effects of change. Unlike mechanical systems, where systems and parts have fixed functions, in resilient places the systems are managed by active social agents. To sustain their resilience these agents have to be willing to engage in cooperative organising. This will make it possible for the place to respond to changed conditions and to fit the changing patterns they encounter in the future. (Lucas, 2004: p. 2).

The prerequisites of such resilient adaptability are a belief shared by stakeholders in the value of the community and place; communication about and participation in decisions made in response to changing conditions; and reliable, up-todate information and analysis of the community and the social, economic and environmental performance of the place and the evaluation of possible change. The development options that will allow the processes of place development to be better delivered will also form part of the body of knowledge needed.

\subsection{Places for enterprising communities}

Places for enterprising communities provide opportunities to creative and enterprising people. The development of a master plan must become a more informed and negotiated process that accommodates the creative enterprise of others. Although the economic aspect is still largely taken for granted (i.e. a development must be profitable to survive) (Rogers, et al., 2012), the success of economic growth and development must not be conceived in the narrow economic terms of profit alone (Bristow, 2010; Hayter, 2004; McInroy and Longlands, 2010). The role of enterprise is being transformed by the integration into the concept of sustainable development as a business opportunity and as a matter of social responsibility (Rogers, et al., 2012: p. 7). Both informal and formal social enterprises, in addition to innovative solutions by commercial agents and public services, are increasingly relevant to contemporary conditions. 'If social capital grows and puts its roots down in successful places - improving the well-being of the place and its people - then other forms of capital will grow there as well' (Adams and Davies, 2012: p. 3). Fostering this requires taking a view of the context, assets (positive features of the place), potential, opportunities for positive change and resources and services required to meet human needs in a just and equitable manner (Newman and Jennings, 2008: p. 32). A whole place view allows an understanding of how the matters that affect a community (the climate and location of the place, the policy and politics that influence and shape it, and the economics and finance that are available to it) can be linked to the assets of a 
community (the local people's collective self-belief, their resources, mobility and skills, the physical environment, and the wider identity of that place) to shape imaginative, placebased solutions. The whole place view is not for the exclusive benefit of big business and local authorities, but should focus on the needs of the community and target neglected niches. Enterprise is best focused on and often targeted at neglected niches. An information-seeking master planning process will readily appreciate the advent of start-ups, which find hitherto unimagined demand and needs.

Enterprises will find successful places are good for business, because successful places sustain local economies by encouraging economic capital to put its roots down too; successful places 'fix' capital, economic as well as social. They are the ground in which a successful and resilient local economy grows. (Adams and Davies, 2012: p. 3)

Accordingly, the practice of master planning should foster the ability of a community and place to be ready for change, adaptable and capable of taking advantage of opportunities (McInroy and Longlands, 2010: p. 10). Local communities should be actively encouraged to engage in a master planning process where citizens are consciously aware of challenges and opportunities and make choices, sharing the decision making responsibilities and the impacts of the process of co-living, coproduction and co-decision as part of urban sustainable development (Paskaleva, 2011).

\subsection{Creating places for collaborative governance}

In collaborative governance multiple stakeholders are engaged in place-based development and use, including the enabling authorities, active developers and engaged communities. 'Successful places come about through the effective coordination of many different actors' (Adams and Davies, 2012: p. 2). The coordinating of the process of local place development has evolved into a complicated practice of disjointed governance. Local development management, roads, building control and other statutory authorities regulate the development activities of landowners and developers. Local communities affected by development proposals have rights to be heard - but only at specific occasions - in the formal regulatory procedures. However, the consultation practices are often ad hoc and reactive. The fragmentation of institutionalised channels of communications and decision-making has attracted criticism for being a cause of the mediocrity of much recent local development. The ability to develop a deep and collective understanding through dialogue, rather than debate, is a mandatory competence needed by future master planning teams if we hope to develop better approaches to sustainable urban development. The nature of this needs to be expressed in a strategic way, which informs processes and engages multidisciplinary approaches through clear vision and strategy to effect social, economic and environmental change (7Group and Reed, 2009). Development governance that is founded in productive dialogue depends on establishing lasting relationships of mutual trust and respect. Engagement (with local stakeholders and communities) in this context is built on establishing secure network relationships. Ethical integrity and transparency in decision-making is vital to this style of governance.

\subsection{Processual planning (planning as a process)}

Planning must be incremental as resources allow and needs require. Monitoring, planning and development must be adaptive and responsive to change. The focus of master planning solutions has hitherto been on finding solutions rather than taking a longer term perspective that ensures continued performance throughout the intended lifespan of the master plan development despite changing conditions (Lombardi et al., 2012). The new master planning toolkit retains an indicative spatial plan as a guide and aid to communicating information, and now must include instruments for monitoring environmental change and development performance and outcomes. The aim of the toolkit is to provide practitioners, policy- and decision-makers access to information on current trends and knowledge gained from past experience regarding development performance, service delivery and outcomes. The toolkit should enable master planning teams to identify problems or challenges, and draw up a strategy for addressing these challenges using information and other resources assembled for this purpose. The master planning process has to motivate stakeholders and ultimately their decisions, provide direction, and secure appropriate actions. The process flows from committing to a long-term development vision combining motivating and feasible goals; formulating an indicative and adaptable spatial plan of links and land uses; making an evolving framework of policies encompassing social, economic and environmental values and principles; and setting out a rolling programme of budgeted projects and provisions for the maintenance of the realised continued delivery. The process needs to be flexible to anticipate and respond to changing conditions and new imperatives. This requires that the process establishes a means of gathering information, analysis and communication across the governance environment. This information is needed for making decisions at the multiple levels and nodal points of this environment. The function of coordination of the process relies on establishing who is to be responsible for the collation and distribution of the information.

\section{Master planning is a long-term process}

Spatial planning in the UK has been criticised as being overconcerned with the end state, and not with how to get there (Falk, 2011: p. 37). 
Urban Design and Planning

Volume 167 Issue DP1
Improving contemporary

approaches to the master

planning process

Al Waer
Numerous documents called masterplans are already produced for many different sites but what is needed is more effective masterplanning, and people who know how to manage and deliver the process successfully. (PAN 83, 2008: p. 4)

In a recent definition Cabe (2011) noted that master planning was a process 'of resolving conflicts and pursuing shared interests creatively - discussing ideas, agreeing objectives and priorities, testing proposals'. This process is very different from the blueprint approach (a linear process to a defined end). Master planning is envisaged as a process of ongoing productive visioning, collaboration, delivery and reassessment. Conceptually, master planning has to be reconceived as a supporting, iterative long-term process of coordination; the purpose of which is to guide the delivery process; resulting in development with feedback loops, accountability and open participation at its heart (Falk, 2011).

There is a need to facilitate the creation and evolution of new 'property development paradigms' (Doak and Karadimitriou, 2007: p. 210). How might we producing resilience by harnessing awareness, enterprise and collaboration in intelligent decision-making?

\subsection{Endorsing commonly held values and principles} The values and principles that need to be endorsed are that the development is sustainable (a strategic perspective); liveable places and fulfilling lives are created (ensuring wellbeing); and the goals are achievable (the pragmatic perspective). Sustainability is not a fixed, perfect state but is an evolving but attainable equilibrium responding to changes in ecological and economic systems as perceived and interpreted by stakeholders (Newman and Jennings, 2008). Additionally, a coordinated master planning process is not an aggregate of environmental, social, economic and technological solutions but it is an emergent process directed towards the purposive and managed interaction of all these systems (du Plessis and Cole, 2011)

\subsection{A common focus}

A common focus permits a process to develop in which stakeholders are engaged and agree to work together to achieve the agreed goals; and relevant stakeholders are engaged and governance maintained over time (custodianship). The master planning process needs to be conceived as functioning like a growing organism in which each decision affects all others and growth is possible as a result of the evolution and consolidation of a multiplicity of actions. What is important is to see the role of the part in the organisation of the whole, to see how the part has both its own identity and, at the same time, its form and behaviour is shaped by participating in systems larger than itself (DeKay, 2011: p. 270). The lesson here is that it is important to consider the whole before agreeing to or designing individual parts and systems. A maturing shared awareness allows participants to interact with growing trust and to build the competences required to understand better how the decisions each participant makes impact on the decisions that all others are making (7Group and Reed, 2009: p. 29). In this perspective 'A master-plan is a series of (decision) and documents ... but more importantly it is a process and a matrix of relationships' (Ardron et al., 2008).

\subsection{A participatory view of stakeholder engagement underpins the master planning process}

Consultation provides three things (Alwaer and Lawlor, 2012; Lawlor, 2011). It creates an authentic story for change. This is best achieved by engaging with people directly about their lives to derive a narrative for the kind of lives they want to lead. The more this is based on their experience and on what they value, the more authentic will be the understanding of developments that are likely to be welcomed and the more powerful its influence. Conversely, the more consultation is about a predetermined change or policy, the weaker will be its lasting impact. The second factor is collaboration by stakeholders to drive change based on the narratives created through the participation process. Stakeholder engagement offers 'a process where diverse stakeholders share a common forum, learn about each other's values and reflect upon their own values and create a shared vision and shared objectives' (Mathur et al., 2008: p. 601). The third factor is pragmatism - an objective way of testing the validity of the community narratives and values because it is the most effective way for the plan to achieve a widely acceptable impact, but it requires pursuing 'a cyclical process facilitating deliberative dialogue between the various stakeholders and is closely linked with the decision-making process in order to explicitly affect key decisions in relation to the future development of an area' (Mathur et al., 2008: p. 607).

These approaches are used to seek answers to a single question: what should drive the action here? Understanding this question enables the right approach to be put in place to achieve the most effective social, economic and cultural impact.

Participative consultation rarely emerges spontaneously. Delivering better master planning demands a facilitating style of leadership that promotes confidence, in turn reducing developer risk, and encouraging developers and other stakeholders to become more innovative and more strongly committed to the quality of place in the delivery process. Without inspirational leadership, the delivery of place relies on the weak authority provided by regulation (Adams et al., 2010). Respect for leadership is won by its practical results. Senior leaders of authorities and development organisations wishing to develop successful sustainable places need to identify, prepare and support individuals who can become effective leaders of the master planning process. 
To be able to build the relationships of trust needed in the planning process such individuals need to be involved in the process over the long term and not to be bought in for shortterm assignments. The characteristic of facilitative leadership requires that these key individuals have exceptional skills. They must be highly effective at relationship building. They must be aware of the technical skills and contributions to be sourced from mixed teams of professionals. They must be able to harness the entrepreneurial genius of developers, business operators and politicians, and appreciate and respect the sensitivities of householders and other groups affected by the changes they are leading. They must be able to inspire, mobilise and guide decision-making. Individuals acquire such competences by working in purposeful organisations led by effective leaders.

\subsection{An evolutionary process}

A long-term planning process is a method of collaborating in and monitoring (managed by use of information) a forum of co-learners within the learning wheel.

\footnotetext{
An agreed direction of travel ... will align and motivate ... authorities, businesses and others around a common purpose, and will provide a basis for developing a strategy, an action programme and method of collaborating, and processes to achieve that intent. (Newman and Jennings, 2008: p. 8)
}

In this process, collaboration is required at multiple levels and participants need to adjust appropriately as the process moves forward through different phases, at varying depths of detail, and respond to different opportunities. The process requires sustaining a constructive alignment of activities and being continuously monitored, accounted for and reviewed (managed by the use of information). The analysis and monitoring component requires a multidimensional and far-seeing approach to analysis and assessment, including the identification of opportunities, threats and risks. Monitoring, review and accountability should be part of the process of developing, learning and improving proposals, policy, programmes and performance (Alwaer and Clements-Croome, 2010; Alwaer and Kirk, 2012; Alwaer et al., 2008a, 2008b). It is a learning activity (Barton et al., 2010). The ongoing monitoring and evaluation value will be fully realised only if it assesses (Barton et al., 2010: p. 48)

\section{the delivery of policy and procedures \\ the effectiveness of the master planning \\ the efficiency of spatial change \\ the sustainability of what has been achieved.}

\section{Discussion and conclusions}

This is the time for a new way of thinking. We need to create a shift in the process of master planning and in thinking about it. Master planning has to be approached as a process of harnessing dynamic forces that are continually in change. It is a positive process that seeks to establish principles for a place changing physically, economically and socially, and who will manage and deliver the process of change. Thus, it is both responsive and proactive (CABE, 2004: p. 33). This view is supported by 7 Group and Reed (2009) who emphasised that this process requires a shift from focusing on the product of the master plan to purposeful systems thinking. It requires

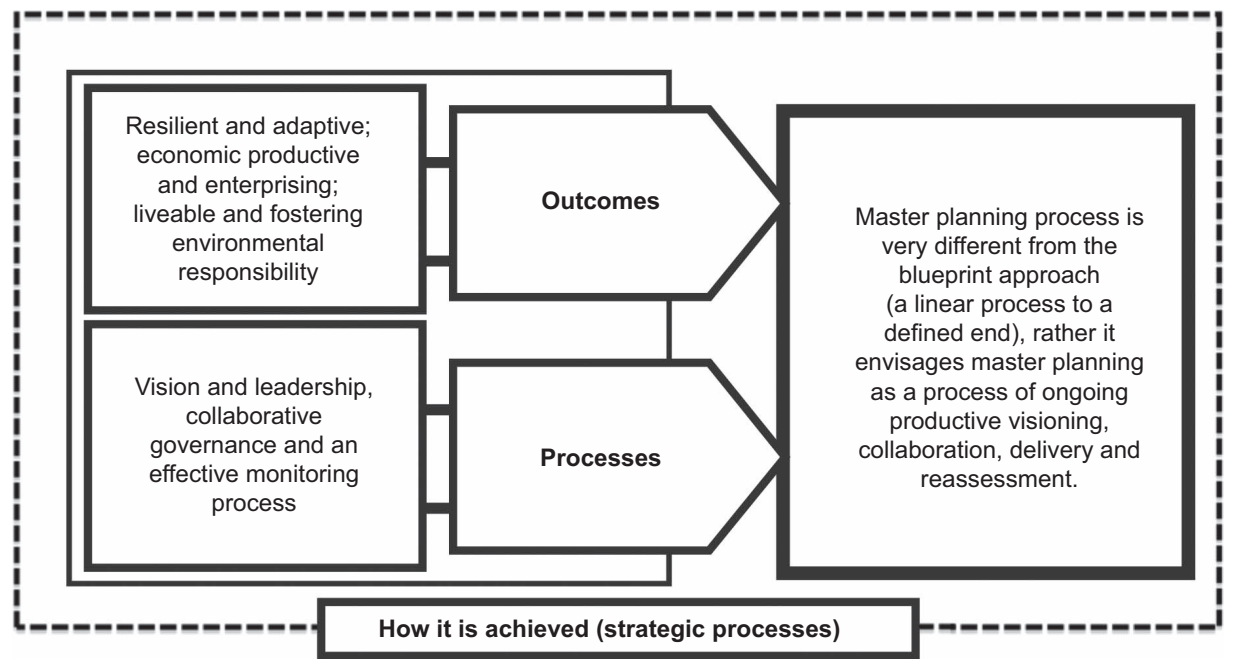

Figure 2. The master planning process is different from the blueprint approach. It can be viewed as a framework supporting a continuous, evolving process that will help guide the delivery of the proposed development 
challenging processes that act as a barrier to achieving better outcomes. These processes have a monitoring and review system, a governance structure (stakeholder decision making) and (business) processes for managing master planning which work to deliver development over lengthy time periods (lengthy because of scarcity of finance). The integrity and integration of processes, and the culture that underpins how processes are used are critical to the delivery process.

The master planning process

includes both the production processes (how it is achieved) and the strategic processes by which it is monitored and directed (information and leadership and governance). The latter start with vision and are continuously concerned with the outcomes (what is being achieved). (Urban Design Protocol, 2011)

The outcomes to be delivered are challenging. They must be resilient and adaptive, economically productive and enterprising, liveable and foster environmental responsibility. The strategic processes require vision and leadership, collaborative governance and an effective monitoring process (see Figure 2).

\footnotetext{
Masterplanning becomes a guiding and co-ordinating role. It provides a route map that connects initial intentions to final outcomes, and offers a clear and tangible visualisation of that outcome, around which a complex production process can be organised. (Madanipour, 2006: p. 20)
}

To shift from a linear approach to an integrated and holistic model is a significant cultural leap that architects, engineers and planners need to make. The journey involves reframing and understanding the interrelationship of people, place and change in an evolutionary way directed towards creating safer, distinctive and sustainable places. The challenge is to reconceive the planning, designing and developmental process, paying particular attention to novel solutions for communication and coordination to achieve the effective transfer from design into realised living settlements (Carmona et al., 2006; Curwell et al., 2005; Deakin, 2009; Egan, 2004). Master planning should be seen as enabling rather than deterministic (after Emes et al., 2012: p. 74).

Adams et al. (2011: p. 4) have proposed that master planning should be pursued as a 'place promoter' with the clear determination to achieve a high quality of place and ensure that the necessary physical and social infrastructure is planned and provided as an integral part of the overall development vision. This paper has reviewed the nature of a master planning process that conforms to the environmental conditions prevailing in the UK in second decade of the twenty-first century. Master planning must be inclusive, strategic, responsive, indicative of opportunities, achievable and informed.
Such a process invites the critical reappraisal of how the development delivery system functions in the present circumstances, but sustainable development requires more than a short-term fix of input factors. The perspective has to emphasise the dynamic and interrelated qualities and context of urban development and to connect immediate and localised concerns to long-term strategic issues.

\section{Acknowledgement}

The author would like to thank Mr David Kirk from the University of Dundee School of the Environment who generously gave his time in reading and commenting on this paper.

\section{REFERENCES}

7Group and Reed B (2009) The Integrative Design Guide to Green Building: Redefining the Practice of Sustainability. John Wiley, Hoboken, NJ, USA.

Adams D and Davies T (2012) Places Need Leaders. Discussion Paper. Architecture and Design Scotland, Edinburgh, Scotland. See http://www.ads.org.uk/urbanism/features/ leadership-is-key-to-creating-better-places (accessed 10/06/ 2012).

Adams D and Tiesdell S (2012) Shaping Places: Urban Planning, Design and Development. Routledge, London, UK.

Adams D, Tiesdell S and Weeks G (2011) Delivering Better Places in Scotland: A Guide to Learning from Broader Experience. Scottish Government, Edinburgh, Scotland.

AlWaer H and Clements-Croome DJ (2010) Key performance indicators (KPIs) and priority setting in using the multi attribute approach for assessing sustainable intelligent buildings. Building and Environment 45(4): 799-807.

AIWaer H and Kirk RD (2012) Building sustainability assessment methods. Proceedings of the Institution of Civil Engineers Engineering Sustainability 165(4): 241-253, http://dx.doi. org/10.1680/ensu.10.00058.

AIWaer H and Lawlor D (2012) Master Planning Process under Current Conditions. Architecture and Design Scotland, Edinburgh. See http://www.ads.org.uk/urbanism/features/ masterplanning-in-current-conditions (accessed 22/12/ 2012).

AlWaer H, Bickerton R and Kirk KD (2013) Examining the components required for assessing the sustainability of communities in the UK. Journal of Architectural and Planning Research, in press.

AlWaer H, Sibley M and Lewis J (2008a) Factors and priorities for assessing sustainability of regional shopping centres in the UK. Architectural Science Review 51(4): 391-402, http://dx.doi.org/10.3763/asre.2008.5135.

AlWaer H, Sibley M and Lewis J (2008b) Different stakeholder perceptions of sustainability assessment. Architectural Science Review 51(1): 47-58. http://dx.doi.org/10.3763/asre. 2008.5107. 
Ardron R, Batty E and Cole I (2008) Devising and Delivering Master-planning at Neighbourhood Level: Some Lessons from the New Deal for Communities Programme. Department for Communities and Local Government, Communities and Local Government Publications, Wetherby, West Yorkshire, UK.

Barton H, Grant M and Guise R (2010) Shaping Neighbourhoods for Local Health and Global Sustainability, 2nd edn. Taylor and Francis, London, UK.

Bell D (2005) The emergence of contemporary masterplans: property markets and the value of urban design. Journal of Urban Design 10(1): 81-110, http://dx.doi.org/10.1080/ 13574800500062387.

Boyko CT, Cooper R and Davey C (2005) Sustainability and the urban design process. Proceedings of the Institution of Civil Engineers - Engineering Sustainability 158(3): 119-125, http://dx.doi.org/10.1680/ensu.2005.158.3.119.

Bristow G (2010) Resilient regions: re-placeing regional competitiveness. Cambridge Journal of Regions, Economy and Society 3(1): 153-167, http://dx.doi.org/167.10.1093/ cjres/rsp030.

CABE (Commission for Architecture and the Built Environment) (2004) Creating Successful Masterplans. CABE, London, UK.

CABE (2011) Creating Successful Masterplans: a Guide for Clients. CABE, London, UK.

Carmona M, Marshall S and Stevens Q (2006) Design codes: their use and potential. Progress in Planning 65(1): 209-289.

Carmona M, Tiesdell S Heath T and Oc T (2010) Public Places Urban Spaces: The Dimensions of Urban Design, 2nd edn. Architectural Press, London, UK.

Cooper I and Symes M (2009) Sustainable Urban Development Vol. 4: Changing Professional Practice. Routledge, London, UK.

Cooper R, Evans G and Boyko C (2009) Designing Sustainable Cities: Decision-Making Tools and Resources for Design. Wiley-Blackwell, London, UK.

Curwell S, Deakin M and Lombardi P (2005) The BEQUEST framework: a vision and methodology. In Sustainable Urban Development Vol. 1, The Framework and Protocols for Environmental Assessment (Curwell S, Deakin M and Symes M (eds)). Routledge, London, UK, pp. 14-34.

DCLG (Department for Communities and Local Government) (2006) Planning Policy Statement 3 (PPS): Housing. HMSO, Norwich, UK.

DCLG (2011) The Localism Act. See https://www.gov.uk/ government/uploads/system/uploads/attachment_data/file/ 5959/1896534.pdf (accessed 14/06/2013).

Deakin M (2009) The search for sustainable communities. In Sustainable Urban Development: The Toolkit for Assessment Vol. 3 (Vreeker R, Deakin M and Curwell S (eds)). Routledge, Oxon, pp. 233-247.
DeKay M (2011) Integral Sustainable Design: Transformative Perspectives. Routledge, London, UK.

Doak J and Karadimitriou N (2007) (Re)development, complexity and networks: a framework for research. Urban Studies 44(2): 209-229.

du Plessis C and Cole RJ (2011) Motivating change: shifting the paradigm. Building Research and Information 39(5): 436449, http://dx.doi.org/10.1080/09613218.2011.582697.

Egan Sir J (2004) Review of Skills for Sustainable Communities. HMSO, London, UK.

Ellin N (2012) Restorative urbanism: from sustainability to prosperity. In Sustainable Urbanism and Beyond (Tigran H (eds)). Rizzoli, New York, USA, pp. 276-281.

Emes MR, Smith A and Marjanovic-Halburd LK (2012) Systems for construction: lessons for the construction industry from experiences in spacecraft systems engineering. Journal of Intelligent Buildings International 4(2): 67-88, http://dx.doi. org/10.1080/17508975.2012.680428.

Falk N (2011) Masterplanning and infrastructure in new communities in Europe. In Urban Design in the Real Estate Development Process (Tiesdell S and Adams D (eds)). Wiley, London, UK, pp. 34-53.

Hayter R (2004) Economic geography as dissenting institutionalism: the embeddedness, evolution and differentiation of regions. Geografiska Annaler, Series B, Human Geography 86(2): 95-115. http://dx.doi.org/10.1111/ j.0435-3684.2004.00156.x.

Lawlor D (2011) Place and Leadership: Promoting 'Delivering Better Places' and the URC Case Studies to the Cross Party Group on Architecture. Architecture and Design Scotland, Edinburgh, UK. See http://www.ads.org.uk/urbanism/ features/place-and-leadership (accessed 30/10/2012).

Lombardi DR, Leach JM, Rogers CDF, Aston R, Barber A et al. (2012) Designing Resilient Cities: A Guide to Good Practice. IHS BRE Press, Watford, UK.

Lucas C (2004) Complex Adaptive Systems - Webs of Delight, Version 4.83, May. See http://www.calresco.org/lucas/cas. htm (accessed 20/10/2012).

Madanipour A (2006) Roles and challenges of urban design. Journal of Urban Design 11(2): 173-193. http://dx.doi.org/ 10.1080/13574800600644035.

Mathur VN, Price ADF and Austin S (2008) Conceptualising stakeholder engagement in the context of sustainability and its assessment. Construction Management and Economics 26(6): 601-209. http://dx.doi.org/10.1080/ 01446190802061233.

McInroy N and Longlands S (2010) Productive Local Economies: Creating Resilient Places. Centre for Local Economic Strategies, Manchester, UK.

Newman P and Jennings I (2008) Cities as Sustainable Ecosystems: Principles and Practices. Island Press, Washington, DC, USA. 
PAN83 (2008) Planning Advice Note: Master Planning. Scottish Government. See http://www.scotland.gov.uk/Resource/ Doc/244134/0068213.pdf (accessed 17/09/2012).

Paskaleva KA (2011) The smart city: a nexus for open innovation? Intelligent Buildings International Journal 3(3): 153-171, http://dx.doi.org/http://dx.doi.org/10.1080/ 17508975.2011.586672.

Roberts P (2009) Sustainable communities, policy, practice and professional development: a model for Europe. In Sustainable Urban Development: Vol. 4, Changing Professional Practice (Cooper I and Symes M (eds)). Routledge, Abingdon, UK, pp. 127-144.

Rogers CDF, Lombardi DR, Leach JM and Cooper RFD (2012) The urban futures methodology applied to urban regeneration. Proceedings of the Institution of Civil Engineers -
Engineering Sustainability: 165(1): 5-20, http://dx.doi.org/ 10.1680/ensu.2012.165.1.37.

Sparks L (2000) Making urban design a key planning issue. Urban Environment Today 11-13. See www.rudi.net/system/ files/file/required_file/6.pdf (accessed 14/06/2013).

Tiesdell S and Adams D (2011) Urban Design in the Real Estate Development Process. Wiley-Blackwell, London, UK.

Trained P (2011) The Bishop Review: The Future of Design in the Built Environment, Project Report. CABE, London, UK Urban Design Protocol (2011) Creating Places for People: an Urban Design Protocol for Australian Cities. Australian Government Publications. See http://www.urbandesign. gov.au/downloads/index.aspx (accessed 26/04/2012).

Urban Task Force (1999) Towards an Urban Renaissance. Taylor and Francis, London, UK.

\section{WHAT DO YOU THINK?}

To discuss this paper, please email up to 500 words to the editor at journals@ice.org.uk. Your contribution will be forwarded to the author(s) for a reply and, if considered appropriate by the editorial panel, will be published as discussion in a future issue of the journal.

Proceedings journals rely entirely on contributions sent in by civil engineering professionals, academics and students. Papers should be 2000-5000 words long (briefing papers should be 1000-2000 words long), with adequate illustrations and references. You can submit your paper online via www.icevirtuallibrary.com/content/journals, where you will also find detailed author guidelines. 